\title{
Diagnóstico e recuperação de manifestações patológicas em alvenarias de vedação de um hospital brasileiro
}

\author{
Diagnosis and recovery of pathologies in masonry wall at a Brazilian hospital \\ Virgínia Queiroz Lira 1,2 (D) https://orcid.org/0000-0002-6155-9559
}

Gabriela Alves Tenório de Morais ${ }^{1,2}$ (iD) https://orcid.org/0000-0001-5132-0483

Marina Macedo de Abreu 1,2 (D) https://orcid.org/0000-0002-4154-1941

Alberto Casado Lordsleem Jr. 1,2 (D) https://orcid.org/0000-0003-3276-0621

1 Escola Politécnica de Pernambuco, Universidade de Pernambuco, Recife, Brasil.
${ }^{2}$ Programa de Pós-graduação em Engenharia Civil, Escola Politécnica de Pernambuco, Brasil.
E-mail do autor principal: Virgínia Lira virginiaqlira@gmail.com

Resumo

A pesquisa objetiva diagnosticar, classificar e elaborar propostas de recuperação para manifestações patológicas em alvenarias de vedação encontradas em um bloco de uma unidade hospitalar. A metodologia envolve o estudo de caso que inclui: revisão da literatura; coleta de dados e análise de informações sobre a edificação; definição do nível da inspeção; realização da vistoria de inspeção; descrição e classificação das manifestações patológicas encontradas através do método de Análise de Modos de Falhas e Efeitos (FMEA); e proposição de técnicas para recuperação. Foram identificadas as seguintes manifestações patológicas: fissuras; umidade e bolor. As principais contribuições deste trabalho são: a descrição das etapas adotadas para elaboração do diagnóstico das manifestações patológicas e a apresentação de propostas de recuperação, um importante instrumento de apoio aos gestores na contratação dos serviços de recuperação.

Palavras-Chave: Manifestações Patológicas; Alvenarias de vedação; Diagnóstico; Recuperação; Hospitais.

\begin{abstract}
This study seeks to diagnose, classify and elaborate proposals for the recuperation of masonry wall pathologies at a hospital. The methodology involves a case study which includes: literature review; data collection and analysis of building information; definition of the inspection level; carrying out the inspection; description and classification of pathological manifestations using the Failure Mode and Effect Analysis (FMEA) method; and recovery proposals. The following pathologies were identified: cracks, humidity and mold. The main contributions of this work are its description of the steps taken to develop the diagnosis of the masonry pathologies and the cataloging of recovery proposals, an important instrument to support building managers when contracting recovery services.
\end{abstract}

Key-words: Building pathologies; Masonry partition walls; Diagnosis; Recuperation; Hospitals. 


\section{Introdução}

As causas das manifestações patológicas são diversas bem como seus efeitos às edificações [1]. Tais manifestações comprometem às edificações sob os pontos de vista estético, de durabilidade e de estanqueidade e tendem a submeter os usuários a constrangimentos [2]. Identificar os mecanismos responsáveis por essas anomalias é imprescindível para determinar a melhor técnica de reparo e o controlar para que não ocorram novamente. [3]

Particularmente, as edificações hospitalares possuem grande importância social e econômica e são tecnicamente complexas [4]. Essas edificações devem ser mantidas em bom estado de conservação e desempenho, principalmente por servirem de abrigo aos enfermos e aos profissionais da saúde. Por prestarem assistência aos pacientes e por serem locais de alto tráfego de pessoas (pacientes, acompanhantes, funcionários do hospital, etc.) exigem rigorosos controles desse fluxo, de limpeza e manutenção dos ambientes. Assim, a higienização dos ambientes é frequente, em geral, utilizando produtos com agentes químicos e processos mecânicos abrasivos, e, com isso, podendo afetar a durabilidade da edificação. [5] No entanto, as edificações hospitalares pertencentes à rede pública de saúde sofrem com a negligência por parte dos órgãos públicos e assim ficam sujeitas à ocorrência de manifestações patológicas. Por outro lado, é consenso que estas edificações devem ser preservadas em bom estado, visto que eles têm como principais usuários e transeuntes, pacientes com a saúde apresentando algum nível de fragilidade. A presença de determinadas manifestações patológicas, como por exemplo, o mofo, pode trazer complicações a saúde dos usuários.[6][7]. Neste âmbito, as alvenarias de vedação têm papel de destaque, uma vez que a salubridade e o conforto de uma edificação estão diretamente associados à qualidade deste elemento do subsistema vedações [8].

Os hospitais demandam atenção quanto à humanização de seus ambientes e à prevenção de infecções, uma vez que tem como objetivo oportunizar as atividades médicas e sobretudo a recuperação dos doentes. Assim, a interrupção das atividades nestas edificações deve ser prevista em projeto, de forma a minimizar interferências nas atividades. Faz-se então imprescindível que nas edificações hospitalares haja previsões de manutenção de forma a que sejam atingidos o desempenho e a vida útil para o qual foram 45 projetadas e ainda para prevenir a ocorrência de manifestações patológicas [6] [9].

Dentro deste contexto, esta pesquisa objetiva diagnosticar, classificar e elaborar propostas de recuperação para as manifestações patológicas das alvenarias de vedação de uma unidade hospitalar do Recife/PE, que atende aproximadamente $55 \%$ de todos os pacientes oncológicos do estado.

\section{Manifestações Patológicas em alvenarias de vedação}

As alvenarias de vedação são um dos elementos do subsistema vedações mais importantes e desempenham papel decisivo para o desempenho das edificações [10]. Este subsistema cumpre funções de proteção e impermeabilização e é responsável por separar os ambientes internos dos externos, de forma que deve resistir às solicitações as quais estiver submetido [8]. Além disso, as vedações verticais servem de suporte e proteção às instalações prediais quando estas forem embutidas [10].

No entanto, para Gonçalves, Brito e Branco [11], por não apresentarem função estrutural, as alvenarias de vedação são muitas vezes esquecidas na etapa de projeto e execução, sendo este um dos fatores que mais tem contribuído para a ocorrência de manifestações patológicas. Silva [12] afirma que a insatisfação dos usuários quanto às alvenarias de vedação é uma reclamação recorrente, assim se faz necessário prevenir as manifestações patológicas de forma antecipada e eficiente, evitando maiores prejuízos aos usuários.

Ressalta-se ainda que os impactos à saúde dos usuários decorrente das manifestações patológicas merecem destaque, dado que a maioria dos fungos que causam bolor são alergênicos e favorecem o aparecimento de doenças como rinite e asma, sobretudo em indivíduos com predisposição a este tipo de disfunção [13] [14].

\section{Utilização de FMEA na construção civil}

A Análise de Modos de Falhas e Efeitos (FMEA), do inglês Failure Mode and Effect Analisys, é uma metodologia de análise de situações de risco. Correia [15] caracteriza a metodologia como uma técnica de análise e gestão de risco, que visa identificar os modos de falhas de um produto, processo ou procedimento, com o intuído de prevenir sua 
ocorrência, atuando antes que a falha se verifique e adotando medidas que minimizem as consequências dessas falhas.

Martins, Pessoa e Nascimento [16] indicam que o Instituto Brasileiro de Avaliações e Perícias de Engenharia recomenda a utilização dos métodos GUT (Gravidade, Urgência e Tendência) ou FMEA como forma de estabelecer a ordem de prioridade no momento de iniciar a recuperação das manifestações patológicas. A prioridade é disposta em ordem decrescente quanto ao grau de risco e intensidade das anomalias e falhas.

O método FMEA é geralmente utilizado nas indústrias seriadas visto que a repetição e a produção em grande escala são predominantes. Para a construção civil, baseada na execução de produtos únicos com características particulares existe uma dificuldade em adaptar os modos de identificação de falhas, pois a cada obra existe um fator predominante diferente, como região, cultura local, estruturação da empresa entre outro. [17]

De acordo com Silva, Fonseca e Brito [18] a aplicabilidade do FMEA na construção civil pode ocorrer em todas as fases (concepção, projeto, construção e manutenção) e nos diferentes subsistemas de um empreendimento. Para o autor, por se tratar de um método sistematizado, proporciona uma reflexão fundamentada em relação aos meios de detecção, prevenção e mitigação das possíveis falhas e seus efeitos.

\section{Metodologia}

A pesquisa em questão trata de um estudo de caso de caráter descritivo [19], pois está interessada em observar fenômenos, procurando descrevê-los, classificá-los e interpretá-los. Para alcançar o objetivo proposto, a metodologia foi dividida nas seguintes etapas:

- Etapa 01 - Revisão da literatura: Buscou-se entender quais as manifestações patológicas possuem maior ocorrência nas vedações verticais, suas causas, origens, mecanismos e métodos de recuperação. Além disso, foi realizado um estudo da norma de inspeção predial [20], e fim de atender as indicações preconizadas.

- Etapa 02 - Vistorias da edificação: Foram disponibilizados pela equipe da edificação as plantas baixas arquitetônicas de todos os pavimentos da edificação, além da planta de localização. Vistorias foram realizadas para inspecionar detalhadamente cada uma das alvenarias.

- Etapa 03 - Compilação das manifestações encontradas, análise das falhas através da metodologia FMEA: No caso da pesquisa em questão, utilizou-se a técnica de aplicação do FMEA proposta por Cupertino e Brandstetter [21]. Os autores adaptaram os parâmetros analisados pelo FMEA para utilização em ocorrência de manifestações patológicas no período pós-obra. Os índices severidade, ocorrência e detecção, geralmente utilizados, foram substituídos por índices que retratam melhor a criticidade da falha no âmbito da construção. Foram utilizados os índices de severidade da falha (S), custo necessário para corrigi-la (C) e complexidade de intervenção da falha (I). O custo estimado para recuperação das manifestações patológicas foi obtido através de orçamento dos serviços necessários com profissionais da área de recuperação. Os índices estão elencados nos Quadros 1, 2 e 3.

Ao final da atribuição dos índices as manifestações patológicas, os coeficientes de prioridade de risco (CPR) foram calculados. O CPR visualiza o grau de risco da manifestação patológica identificada através da multiplicação dos índices de severidade, custo e complexidade de intervenção, conforme Equação (1).

$$
\mathrm{CPR}=\mathrm{S} * \mathrm{C} * \mathrm{I}
$$

CPR: coeficiente de prioridade de risco;

$\mathrm{S}$ : índice de severidade;

C: índice de custo;

I: índice de complexidade de intervenção.

A partir do cálculo do CPR é atribuído a cada manifestação patológica seu grau de risco, conforme apresentado no Quadro 4, a fim de se realizar um melhor plano de intervenção.

- Etapa 4 - Proposição de reparos: Foram propostas técnicas de reparo para todas as manifestações patológicas identificadas.

Quadro 1: Índices de severidade

\begin{tabular}{|ccc|}
\hline Índice & Severidade & Critério \\
\hline 1 & Pequena & $\begin{array}{c}\text { Ligeira deterioração ou queda no } \\
\text { desempenho do sistema com leve } \\
\text { descontentamento do cliente. }\end{array}$ \\
\hline 2 & Moderada & $\begin{array}{c}\text { Deterioração significativa no } \\
\text { desempenho do sistema com } \\
\text { descontentamento do cliente }\end{array}$ \\
\hline 3 & Alta & $\begin{array}{c}\text { Sistema deixa de funcionar gerando } \\
\text { grande descontentamento do cliente. }\end{array}$ \\
\hline 4 & Muito Alta & $\begin{array}{c}\text { Sistema deixa de funcionar gerando } \\
\text { grande descontentamento do cliente e } \\
\text { afetando a segurança do mesmo }\end{array}$ \\
\hline
\end{tabular}

Fonte: Cupertino e Brandstetter, 2015. 
Quadro 2: Índices de custo

\begin{tabular}{|ccl|}
\hline Índice & Custo & Critério \\
\hline 1 & Pequeno & Gastos entre $\mathrm{R} \$ 0,01$ a $\mathrm{R} \$ 450,00$ \\
\hline 2 & Moderado & Gastos entre $\mathrm{R} \$ 451,00$ a $\mathrm{R} \$ 1300,00$ \\
\hline 3 & Alto & Gastos entre $\mathrm{R} \$ 1301,00$ a $\mathrm{R} \$ 3000,00$ \\
\hline 4 & Muito Alto & Gastos acima de 3000,00 \\
\hline
\end{tabular}

Fonte: Cupertino e Brandstetter, 2015.

Quadro 3: Índices de intervenção

\begin{tabular}{|c|c|c|}
\hline Índice & $\begin{array}{c}\text { Complexidade } \\
\text { de } \\
\text { intervenção }\end{array}$ & Critério \\
\hline 1 & Simples & $\begin{array}{l}\text { Intervenção realizada em uma única } \\
\text { operação pontual do sistema sem a } \\
\text { necessidade de intervenção em } \\
\text { outros sistemas. }\end{array}$ \\
\hline 2 & Média & $\begin{array}{l}\text { Intervenção moderada do sistema } \\
\text { podendo ou não ter a necessidade de } \\
\text { intervenção em outro sistema } \\
\text { gerando pequenas correções no } \\
\text { mesmo. }\end{array}$ \\
\hline 3 & Difícil & $\begin{array}{l}\text { Intervenção significativa do sistema } \\
\text { com a necessidade de intervenção } \\
\text { em outros sistemas gerando } \\
\text { demolição do sistema para correções } \\
\text { e reexecução do mesmo. }\end{array}$ \\
\hline 4 & Muito difícil & $\begin{array}{l}\text { Intervenção significativa do sistema } \\
\text { com necessidade de intervenção em } \\
\text { mais de um sistema gerando quebra, } \\
\text { reexecução, reforços estruturais ou } \\
\text { reabilitação dos mesmos. }\end{array}$ \\
\hline
\end{tabular}

Fonte: Cupertino e Brandstetter, 2015.

Quadro 4: Grau de risco

\begin{tabular}{|c|c|c|}
\hline $\begin{array}{l}\text { Prioridade } \\
\text { de risco }\end{array}$ & $\begin{array}{l}\text { Intervalo de } \\
\text { valores }\end{array}$ & $\begin{array}{l}\text { Grau de urgência das } \\
\text { intervenções }\end{array}$ \\
\hline Baixo & $\mathrm{CPR} \leq 4$ & $\begin{array}{c}\text { Devem ser tomadas medidas de } \\
\text { intervenções para melhoria sem } \\
\text { caráter de urgência }\end{array}$ \\
\hline Moderado & $4<\mathrm{CPR} \leq 16$ & $\begin{array}{l}\text { Devem ser tomadas medidas de } \\
\text { intervenções logo que possível, } \\
\text { visando diminuir a probabilidade } \\
\text { de ocorrência dos danos em } \\
\text { empreendimentos futuros. }\end{array}$ \\
\hline Elevado & $\begin{array}{c}16<\mathrm{CPR} \leq \\
32\end{array}$ & $\begin{array}{l}\text { Devem ser tomadas medidas } \\
\text { corretivas visando eliminar as } \\
\text { causas das manifestações } \\
\text { patológicas detectadas, evitando a } \\
\text { ocorrência das mesmas em } \\
\text { empreendimentos futuros. }\end{array}$ \\
\hline $\begin{array}{l}\text { Muito } \\
\text { Elevado }\end{array}$ & $\begin{array}{c}32<\mathrm{CPR} \\
64\end{array}$ & $\begin{array}{l}\text { Requer ações corretivas imediatas } \\
\text { para eliminação das causas, com } \\
\text { análise crítica das etapas que se } \\
\text { relacionam com o serviço e } \\
\text { controle, para que tais } \\
\text { manifestações patológicas não } \\
\text { ocorram em empreendimentos } \\
\text { futuros. }\end{array}$ \\
\hline
\end{tabular}

Fonte: Cupertino e Brandstetter, 2015.

\section{Resultados}

\subsection{Vistorias da edificação: coleta de subsídios e anamnese}

O hospital objeto de estudo tem 70 anos de serviços prestados à população pernambucana, atendendo cerca de $55 \%$ dos pacientes oncológicos de todo o estado. A área útil do hospital totaliza 23.080 $\mathrm{m}^{2}$, onde estão situados 14 blocos que abrigam as atividades do hospital. O bloco onde foram realizadas as análises foi o bloco 13, o qual atualmente abriga as enfermarias, bloco cirúrgico e tratamento de quimioterapia

A edificação em questão é composta por 4 pavimentos, que abrigam o bloco cirúrgico (térreo), a área destinada ao tratamento de quimioterapia $\left(1^{\circ}\right.$ pavimento), e as áreas destinadas a internação de pacientes, as enfermarias ( $2^{\circ}$ e $3^{\circ}$ pavimentos). Cada pavimento tem área construída de aproximadamente $740 \mathrm{~m}^{2}$. A área efetiva utilizada como estudo de caso foi de $2.220 \mathrm{~m}^{2}$ (excluindo apenas o pavimento de realização das cirurgias, pela impossibilidade de visitação). A edificação tem estrutura em concreto armado e vedações em alvenaria de bloco cerâmico com revestimento de argamassa.

Durante a coleta de dados foram fornecidas informações relevantes para que se possa entender 0 estudo de caso:

- toda a verba que mantem o hospital, inclusive os custos com manutenção e operação da edificação, vem dos repasses feitos pelo SUS (Sistema Único de Saúde) e de doações feitas da população e empresas, visto que todos os tratamentos do hospital são feitos de forma gratuita;

- o pavimento térreo tem acesso restrito por se tratar do bloco onde ocorrem as cirurgias;

- o primeiro pavimento é onde ocorre o tratamento de quimioterapia e as consultas médicas. Sendo assim, é o pavimento de maior fluxo de pessoas, visto que recebe diferentes pacientes diariamente. $O$ pavimento passou por reformas realizadas previamente à vistoria, onde pequenas salas foram transformadas numa sala maior em que os pacientes recebem a quimioterapia. Foram também colocadas pingadeiras na face exterior de algumas esquadrias. 
- o segundo pavimento abriga enfermarias. 0 pavimento também já passou por reformas. Inicialmente cada quarto era dedicado a somente um paciente. Após os serviços do hospital serem destinados apenas a pacientes da rede pública de saúde os quartos individuais se transformaram em enfermarias, suas divisões foram retiradas, transformando em vãos maiores que abrigam mais de um paciente por enfermaria. Além disso, uma segunda reforma foi realizada por solicitação da Agência Nacional de Vigilância Sanitária (ANVISA), onde foi trocado todo o revestimento do piso e paredes do pavimento, que atualmente é revestimento cerâmico.

- o terceiro pavimento também tem utilização de enfermaria, e passou pelas mesmas reformas no segundo, no sentido de terem os quartos particulares transformados em enfermarias coletivas. Em relação ao revestimento, ele conta com um revestimento de fórmica nas áreas comuns, revestimento este que deve ser trocado o mais rápido possível, por determinação da ANVISA. Dentro das enfermarias o revestimento é de argamassa com pintura;

- todas as enfermarias possuem arcondicionado do tipo split. A instalação de arescondicionados é recente, caracterizando que as alvenarias sofreram posterior intervenção para instalação das máquinas;

Após todas as informações coletadas acerca do estudo de caso, foi possível caracterizá-lo como inspeção de Nível 2, a qual é adotada para edificações multifamiliares e comerciais que não disponham de sistemas construtivos complexos, como climatização e automação. E normalmente envolve equipe multidisciplinar [20].

\subsection{Problemas identificados}

Após a realização da vistoria foi possível identificar todas as manifestações patológicas existentes nas alvenarias do bloco 13 do hospital. Foram localizadas na planta arquitetônica de cada pavimento, quais paredes devem ser recuperadas e nelas foram indicadas quais manifestações patológicas ocorreram (Figuras 1,2 e 3 ). O Quadro 5 caracteriza as manifestações patológicas encontradas na edificação hospitalar e aplica a metodologia FMEA para classificação de sua criticidade.

Percebe-se que as manifestações patológicas mais frequentes na edificação são provenientes da presença de umidade, seja da fachada, dos arescondicionados ou das instalações hidrossanitárias. A maioria das ocorrências poderiam ter sido evitadas através da execução de manutenção periódica na edificação.

Figura 1: Manifestações patológicas no $1^{\circ}$ pavimento.

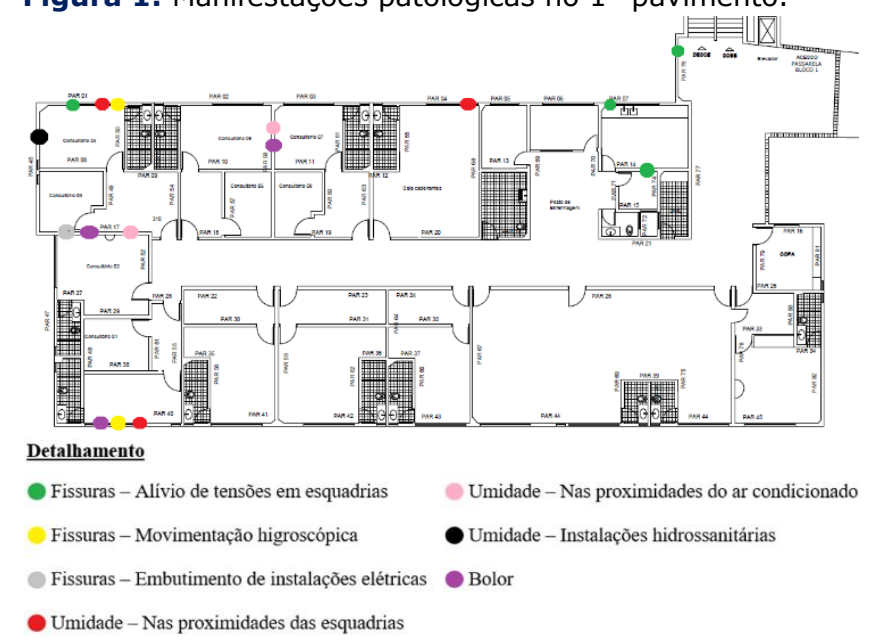

Figura 2: Manifestações patológicas no $2^{\circ}$ pavimento.

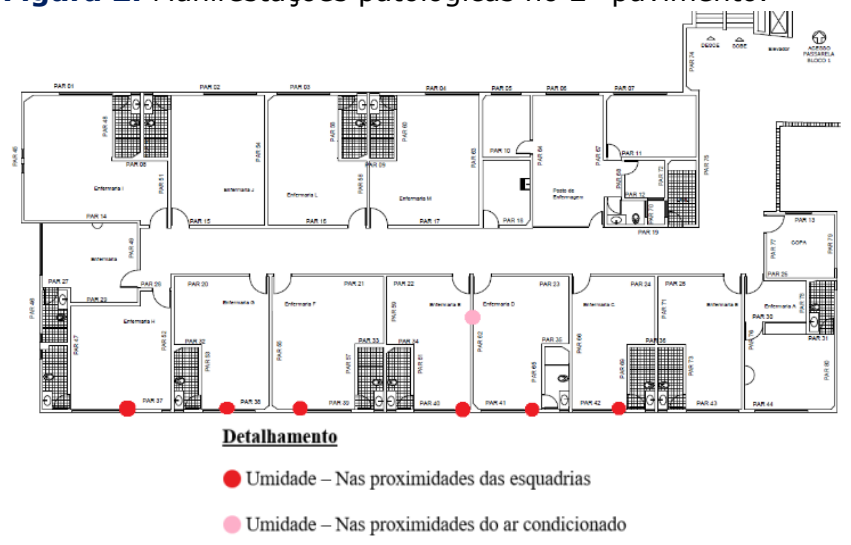

Figura 3: Manifestações patológicas no $3^{\circ}$ pavimento.

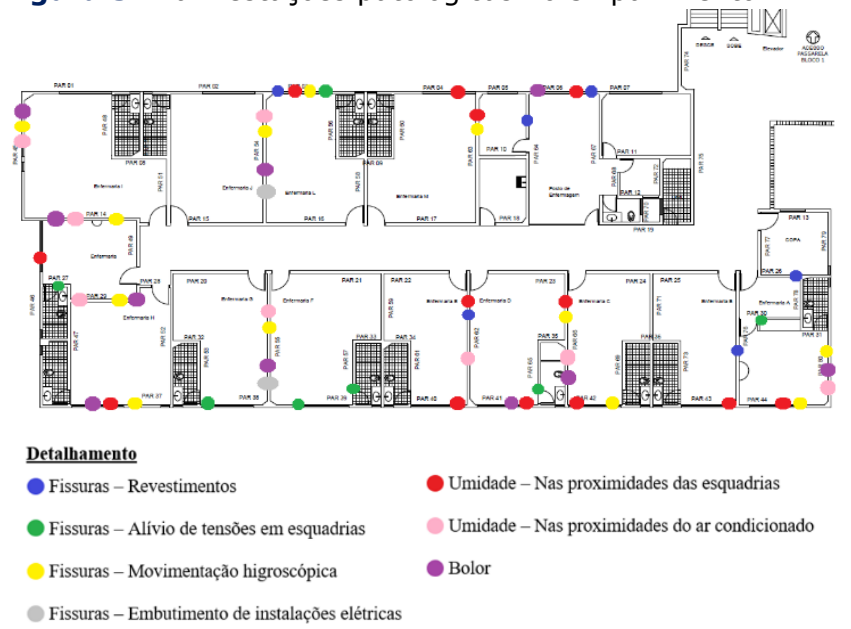

DOI: 10.25286/repa.v6i1.1388 
Ainda sobre a importância da manutenção, os pavimentos onde houve algum tipo de intervenção recente, tais como o primeiro pavimento, onde houve reforma de algumas salas e o segundo onde foi aplicado revestimento cerâmico em todas as paredes, teve uma quantidade muito menor de manifestações patológicas. Já o terceiro pavimento, onde não ouve nenhuma manutenção recente, há maior quantidade de manifestações patológicas.

A partir da aplicação da metodologia FMEA foi possível elencar uma ordem de prioridade para realizar o reparo das manifestações patológicas encontradas (Quadro 6).

A análise mostra que a maior parte das manifestações patológicas encontradas na edificação são de grau de risco moderado, seguidas pelas de risco elevado e de risco baixo. Não tendo nenhuma ocorrência caracterizada com um risco muito alto.

\subsection{Propostas de reparo}

Com base nos dados coletados na literatura científica, foram indicadas propostas de recuperações para as manifestações patológicas encontradas na edificação hospitalar objeto de estudo.

\subsubsection{Fissuras}

O conhecimento das causas que originaram as fissuras é fundamental para definição da proposta de reparo adequada, uma vez que é necessário compreender e intervir primeiramente nas causas que provocaram seu aparecimento [8] [22] [23].

Lordsleem Jr. [22] define como sistema de recuperação "o conjunto de camadas que uma vez aplicadas restituem à vedação vertical, no caso constituída pela alvenaria de vedação com revestimento de argamassa, as funções para a qual ela foi construída".

A pesquisa de Lordsleem Jr. [22], estudou à capacidade de deformação de sistemas de recuperação face à atividade das fissuras de alvenaria de vedações e identificou que o sistema proposto por Franco e Aly (1989 apud Lordsleem Jr. [22]), dentre os avaliados, demonstrou melhor desempenho quanto à capacidade de deformação. De forma que esta pesquisa indica o referido sistema como proposta de reparo para as fissuras identificadas. As etapas de execução desta recuperação podem ser encontradas detalhadamente na referência citada.

\subsubsection{Umidade}

De acordo com Paz et al. [20] é imprescindível que antes da aplicação de qualquer técnica de reparo para a presença de umidade, seja realizado previamente a identificação dos pontos onde estão ocorrendo as infiltrações, das causas das infiltrações e da eliminação destas.

Uma das principais técnicas utilizadas para solucionar a umidade em alvenarias é a aplicação de revestimentos de argamassas de recuperação. Esta solução tem como vantagens o baixo custo e a de fácil aplicação. Este tipo de revestimento é impermeável a água e permeável ao vapor, de forma que ao mesmo tempo que impedem a entrada da água, permitem que a secagem do substrato [24].

De forma que a solução adotada por este autor é indicada como técnica de reparo nesta pesquisa. No trabalho de Posser [24] são detalhadas todas as etapas necessárias para essa aplicação.

\subsubsection{Bolor}

Guerra et al. [14] afirma que na prática, tende-se a solucionar o aparecimento de bolores através da aplicação de fungicidas ou tintas especiais com microbicidas, porém, caso as causas desta manifestação patológica não sejam combatidas, a utilização destes produtos apresentará tempo limitado de ação e a falha voltará a ocorrer em curto prazo.

A presente pesquisa sugere como proposta de reparo as etapas presentes no trabalho de Paz et al. [25]. A solução que deve ser utilizada na limpeza das áreas danificadas, é composta por hipoclorito de sódio e água, na proporção $1: 1$, proposta por Cunha et al. [1].

\section{Conclusões}

Dadas as manifestações patológicas detectadas através da inspeção da edificação, acredita-se que as causas das mesmas poderiam ter sido eliminadas através de maior detalhamento e melhor especificação na etapa de projeto, bem como através da execução de manutenções preventivas. 


\begin{tabular}{|c|c|c|c|c|c|c|c|c|c|c|c|c|}
\hline \multirow{2}{*}{\begin{tabular}{l|}
$\mathbf{G}$ \\
$\mathbf{r}$ \\
$\mathbf{u}$ \\
$\mathbf{p}$ \\
$\mathbf{o}$ \\
\end{tabular}} & \multirow[b]{2}{*}{ Descrição } & \multirow[b]{2}{*}{$\begin{array}{l}\text { Característica } \\
\text { Visual }\end{array}$} & \multirow[b]{2}{*}{ 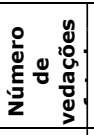 } & \multirow[b]{2}{*}{ 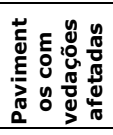 } & \multirow[b]{2}{*}{ Causa } & \multirow[b]{2}{*}{ Efeito } & \multirow[b]{2}{*}{$\begin{array}{c}\text { Severid } \\
\text { ade }\end{array}$} & \multirow[b]{2}{*}{ Custo } & \multirow[b]{2}{*}{$\begin{array}{l}\text { Complexid } \\
\text { ade de } \\
\text { Intervenç } \\
\text { ão }\end{array}$} & \multicolumn{2}{|c|}{ Prioridade de risco } & \multirow[b]{2}{*}{ Medidas de controle } \\
\hline & & & & & & & & & & $\begin{array}{l}\text { Magnitud } \\
\text { e de } \\
\text { risco }\end{array}$ & $\begin{array}{l}\text { Grau de } \\
\text { risco }\end{array}$ & \\
\hline \multirow{5}{*}{1} & \multirow{5}{*}{$\begin{array}{l}\text { Manchas de } \\
\text { umidade e } \\
\text { fissuras } \\
\text { próximas a } \\
\text { janelas }\end{array}$} & \multirow{5}{*}{ 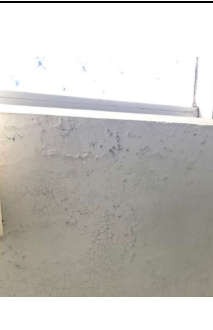 } & \multirow{5}{*}{22} & \multirow{5}{*}{$\begin{array}{c}1^{\circ}, 2^{\circ} \mathrm{e} \\
3^{\circ}\end{array}$} & $\begin{array}{l}\text { Ausência de vedação da } \\
\text { esquadria }\end{array}$ & Problemas estéticos & \multirow{5}{*}{3} & \multirow{5}{*}{2} & \multirow{5}{*}{3} & \multirow{5}{*}{18} & \multirow{5}{*}{ 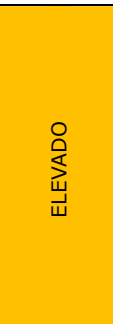 } & Utilizar selantes para vedação de esquadria. \\
\hline & & & & & $\begin{array}{c}\text { Ausência de manutenção } \\
\text { periódica na vedação da } \\
\text { esquadria }\end{array}$ & Infiltrações & & & & & & $\begin{array}{l}\text { Utilizar rejunte adequado na cerâmica da } \\
\text { fachada. }\end{array}$ \\
\hline & & & & & \multirow{3}{*}{$\begin{array}{l}\text { Ausência de manutenção no } \\
\text { rejunte do revestimento da } \\
\text { fachada }\end{array}$} & Falta de & & & & & & Controlar o assentamento do revestimento. \\
\hline & & & & & & $\begin{array}{l}\text { estanqueidade as } \\
\text { intempéries }\end{array}$ & & & & & & Especificar a vida útil e manutenção da \\
\hline & & & & & & $\begin{array}{l}\text { Defeitos na pintura } \\
\text { e no reboco }\end{array}$ & & & & & & $\begin{array}{l}\text { fachada no memorial de uso, operação e } \\
\text { manutenção da edificação }\end{array}$ \\
\hline \multirow{4}{*}{2} & \multirow{4}{*}{$\begin{array}{l}\text { Manchas de } \\
\text { umidade e } \\
\text { fissuras } \\
\text { próximas } \\
\text { aos ares- } \\
\text { condicionad } \\
\text { os }\end{array}$} & & \multirow{4}{*}{11} & \multirow{4}{*}{$\begin{array}{l}10,2^{\circ} \mathrm{e} \\
3^{\circ}\end{array}$} & Ausência de manutenção & \multirow{4}{*}{$\begin{array}{l}\text { Problemas estéticos } \\
\text { Infiltraçós } \\
\text { Defeitos na pintura } \\
\text { e no reboco }\end{array}$} & \multirow{4}{*}{2} & \multirow{4}{*}{2} & \multirow{4}{*}{3} & \multirow{4}{*}{12} & \multirow{4}{*}{ 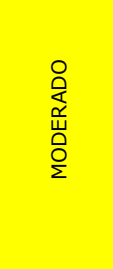 } & Realizar projeto detalhado de climatização. \\
\hline & & & & & $\begin{array}{l}\text { condicionado } \\
\text { chent }\end{array}$ & & & & & & & $\begin{array}{l}\text { Compatibilizar projeto de climatização com } \\
\text { projeto de hidrossanitário (drenagem). }\end{array}$ \\
\hline & & & & & & & & & & & & $\begin{array}{c}\text { Controlar qualidade dos serviços de instalação } \\
\text { realizados. }\end{array}$ \\
\hline & & & & & $\begin{array}{l}\text { Ausencia de drenagem no ar } \\
\text { condicionado }\end{array}$ & & & & & & & $\begin{array}{l}\text { Detalhar no manual de uso, operação e } \\
\text { manutenção como devem ser feitas as } \\
\text { instalaçôes de ares condicionados. }\end{array}$ \\
\hline & & & & & $\begin{array}{l}\text { Ausência de vedação da } \\
\text { esquadria }\end{array}$ & & & & & & & Utilizar selantes para vedação de esquadria. \\
\hline & $\begin{array}{l}\text { Bolor nas } \\
\text { áreas } \\
\text { próximas as }\end{array}$ & & & & $\begin{array}{l}\text { Ausência de manutenção } \\
\text { periódica na vedação da } \\
\text { esquadria }\end{array}$ & & & & & & & $\begin{array}{l}\text { Utilizar rejunte adequado no revestimento da } \\
\text { fachada. }\end{array}$ \\
\hline & $\begin{array}{l}\text { aos ares- } \\
\text { condicionad } \\
\text { os }\end{array}$ & & & & $\begin{array}{l}\text { Ausência de manutenção no } \\
\text { rejunte do revestimento da } \\
\text { fachada }\end{array}$ & & & & & & & Controlar o assentamento do revestimento. \\
\hline 3 & & & 13 & $1^{\circ}$ e $3^{\circ}$ & $\begin{array}{l}\text { Ausência de manutenção } \\
\text { periódica na drenagem do ar } \\
\text { condicionado }\end{array}$ & $\begin{array}{c}\text { Problemas estéticos } \\
\text { Defeitos na pintura } \\
\text { e reboco } \\
\text { Problemas de } \\
\text { saúde aos usuários }\end{array}$ & 1 & 1 & 1 & 1 & 底 & $\begin{array}{l}\text { Especificar a vida útil e manutenção da } \\
\text { vedação das esquadrias e do rejunte da } \\
\text { fachada no memorial de uso, operação e } \\
\text { manutenção da edificação. }\end{array}$ \\
\hline & & & & & & & & & & & & Realizar projeto detalhado de climatização. \\
\hline & & & & & & & & & & & & $\begin{array}{l}\text { Compatibilizar projeto de climatização com } \\
\text { projeto de hidrossanitário (drenagem). }\end{array}$ \\
\hline & & & & & $\begin{array}{l}\text { Ausencia de drenagem no ar } \\
\text { condicionado }\end{array}$ & & & & & & & $\begin{array}{l}\text { Controlar qualidade dos serviços de instalação } \\
\text { realizados. }\end{array}$ \\
\hline & & & & & & & & & & & & $\begin{array}{l}\text { Detalhar no manual de uso, operação e } \\
\text { manutenção como devem ser feitas as } \\
\text { instalações de ares condicionado. }\end{array}$ \\
\hline
\end{tabular}




\begin{tabular}{|c|c|c|c|c|c|c|c|c|c|c|c|c|}
\hline \multirow{2}{*}{\begin{tabular}{l|}
$\mathbf{G}$ \\
$\mathbf{r}$ \\
$\mathbf{u}$ \\
$\mathbf{p}$ \\
$\mathbf{0}$
\end{tabular}} & \multirow[b]{2}{*}{ Descrição } & \multirow[b]{2}{*}{ Característica Visual } & \multirow{2}{*}{$\begin{array}{l}\text { Número de } \\
\text { vedações } \\
\text { afetadas }\end{array}$} & \multirow{2}{*}{$\begin{array}{l}\text { Pavimentos com } \\
\text { vedações } \\
\text { afetadas }\end{array}$} & \multirow[b]{2}{*}{ Causa } & \multirow[b]{2}{*}{ Efeito } & \multirow[b]{2}{*}{$\begin{array}{l}\text { Severi } \\
\text { dade }\end{array}$} & \multirow[b]{2}{*}{ Custo } & \multirow{2}{*}{$\begin{array}{c}\text { Complex } \\
\text { idade de } \\
\text { Interven } \\
\text { ção }\end{array}$} & \multicolumn{2}{|c|}{$\begin{array}{c}\text { Prioridade de } \\
\text { risco }\end{array}$} & \multirow[b]{2}{*}{ Medidas de controle } \\
\hline & & & & & & & & & & $\begin{array}{c}\text { Magnit } \\
\text { ude de } \\
\text { risco }\end{array}$ & $\begin{array}{c}\text { Grau } \\
\text { de } \\
\text { risco }\end{array}$ & \\
\hline \multirow{4}{*}{4} & \multirow{4}{*}{$\begin{array}{c}\text { Manchas de } \\
\text { umidade - } \\
\text { Instalações } \\
\text { Hidrossanitá } \\
\text { rias }\end{array}$} & & \multirow{4}{*}{01} & \multirow{4}{*}{$1^{\circ}$} & \multirow{4}{*}{$\begin{array}{l}\text { Vazamento nas } \\
\text { instalações } \\
\text { hidrossanitárias }\end{array}$} & $\begin{array}{l}\text { Problemas } \\
\text { estéticos }\end{array}$ & \multirow{4}{*}{2} & \multirow{4}{*}{2} & \multirow{4}{*}{3} & \multirow{4}{*}{12} & \multirow{4}{*}{ 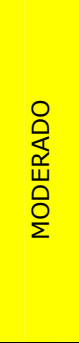 } & \multirow{2}{*}{$\begin{array}{l}\text { Solicitar que os } \\
\text { projetos } \\
\text { hidrossanitários sejam } \\
\text { mais detalhados para } \\
\text { não gerar dúvidas. }\end{array}$} \\
\hline & & & & & & Infiltrações & & & & & & \\
\hline & & $x$ & & & & $\begin{array}{c}\text { Falta de } \\
\text { estanqueidade }\end{array}$ & & & & & & Controlar a execução \\
\hline & & & & & & $\begin{array}{l}\text { Defeitos na } \\
\text { pintura e no } \\
\text { reboco }\end{array}$ & & & & & & $\begin{array}{c}\text { instalaç̃̃es } \\
\text { hidrossanitárias. }\end{array}$ \\
\hline \multirow[b]{2}{*}{5} & \multirow{2}{*}{$\begin{array}{c}\text { Fissura por } \\
\text { rasgo para } \\
\text { embutiment } \\
\text { o de } \\
\text { instalações } \\
\text { elétricas }\end{array}$} & & \multirow[b]{2}{*}{03} & \multirow[b]{2}{*}{$1^{\circ}$ e $3^{\circ}$} & $\begin{array}{l}\text { Locação da } \\
\text { instalação } \\
\text { elétrica não foi } \\
\text { pensada na } \\
\text { fase de projeto }\end{array}$ & $\begin{array}{l}\text { Problemas } \\
\text { estéticos }\end{array}$ & \multirow[b]{2}{*}{2} & \multirow[b]{2}{*}{2} & \multirow[b]{2}{*}{3} & \multirow[b]{2}{*}{12} & \multirow{2}{*}{ 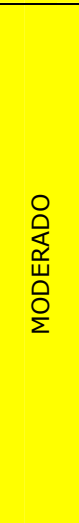 } & $\begin{array}{l}\text { Solicitar que os } \\
\text { projetos elétricos } \\
\text { tenham maior } \\
\text { compatibilização com } \\
\text { a necessidade de } \\
\text { utilização dos } \\
\text { usuários. }\end{array}$ \\
\hline & & & & & $\begin{array}{l}\text { Má execução } \\
\text { do rasgo e } \\
\text { posterior } \\
\text { reboco de } \\
\text { cobertura do } \\
\text { mesmo }\end{array}$ & $\begin{array}{l}\text { Defeito na pintura e } \\
\text { reboco }\end{array}$ & & & & & & $\begin{array}{c}\text { Inserir no manual de } \\
\text { uso, operação e } \\
\text { manutenção, quais os } \\
\text { procedimentos que } \\
\text { deverão ser realizados } \\
\text { quando houver } \\
\text { necessidade de } \\
\text { alteração da instalação } \\
\text { elétrica. }\end{array}$ \\
\hline \multirow[t]{2}{*}{6} & \multirow{2}{*}{$\begin{array}{l}\text { Fissuras em } \\
\text { vãos de } \\
\text { portas e } \\
\text { esquadrias }\end{array}$} & & \multirow[t]{2}{*}{10} & \multirow[t]{2}{*}{$1^{\circ}$ e $3^{\circ}$} & $\begin{array}{l}\text { Ausência de } \\
\text { especificaçãão } \\
\text { de vergas e } \\
\text { contra-vergas } \\
\text { em projeto. }\end{array}$ & $\begin{array}{l}\text { Problemas } \\
\text { estéticos }\end{array}$ & \multirow[t]{2}{*}{1} & \multirow[t]{2}{*}{2} & 3 & 6 & $\begin{array}{l}\text { 을 } \\
\text { 宅 } \\
\text { 岀 }\end{array}$ & $\begin{array}{c}\text { Solicitar que os } \\
\text { projetistas detalhem a } \\
\text { utilização de vergas e } \\
\text { contra-vergas nos } \\
\text { vãos de portas e } \\
\text { janelas. }\end{array}$ \\
\hline & & & & & $\begin{array}{l}\text { Não execução } \\
\text { de vergas e } \\
\text { contra-vergas } \\
\text { especificadas } \\
\text { em projeto }\end{array}$ & $\begin{array}{l}\text { Defeito na pintura } \\
\quad \text { e reboco }\end{array}$ & & & & & $\sum$ & $\begin{array}{c}\text { Controlar a execução } \\
\text { dos serviços de } \\
\text { alvenaria para que } \\
\text { esses elementos sejam } \\
\text { utilizados. }\end{array}$ \\
\hline
\end{tabular}


Quadro 6: Ordem de reparo das manifestações de acordo com a metodologia FMEA

\begin{tabular}{|ccc|}
\hline Manifestação patológica & CPR & $\begin{array}{c}\text { Grau de } \\
\text { risco }\end{array}$ \\
\hline $\begin{array}{c}\text { Manchas de umidade e fissuras } \\
\text { próximas a janelas }\end{array}$ & 18 & ELEVADO \\
\hline $\begin{array}{c}\text { Manchas de umidade e fissuras } \\
\text { próximas aos ares-condicionados }\end{array}$ & 12 & MODERADO \\
\hline $\begin{array}{c}\text { Manchas de umidade - Instalações } \\
\text { Hidrossanitárias }\end{array}$ & 12 & MODERADO \\
\hline $\begin{array}{c}\text { Fissura por rasgo para embutimento de } \\
\text { instalações elétricas }\end{array}$ & 12 & MODERADO \\
\hline Fissuras em vãos de portas e esquadrias & 6 & MODERADO \\
\hline $\begin{array}{c}\text { Bolor nas áreas próximas as janelas e } \\
\text { aos ares-condicionados }\end{array}$ & 1 & BAIXO \\
\hline
\end{tabular}

Ainda que as manifestações patológicas não comprometam a segurança estrutural da edificação em questão é evidente que geram desconforto aos usuários, que neste caso, em sua maioria são pacientes já extremamente debilitados. O mal-estar em relação às instalações pode ser verificado pelas recorrentes reclamações dos usuários durante as vistorias.

No intuito de auxiliar no gerenciamento das atividades de reparo, propõe-se que os gestores sigam a ordem de prioridade sugerida através do grau de risco das manifestações patológicas. Sendo este um parâmetro confiável, já que está baseado na metodologia FMEA, amplamente discutida e validada pela literatura científica.

Cabe ressaltar que, mesmo diante do empenho dos profissionais ligados a gerência do hospital em manter o funcionamento de todas as áreas, preservando ao máximo o conforto dos pacientes, faz-se necessário a existência de investimentos por parte do governo de forma a subsidiar as devidas condições de uso para a edificação. Tendo em vista sobretudo o impacto social que o hospital objeto de estudo tem ao atender quase $55 \%$ dos casos de câncer do estado de Pernambuco.

Ademais, ainda que haja dificuldades financeiras, o hospital deve desenvolver um plano de manutenção predial baseado nas normas técnicas, eficiente e coerente com a realidade da edificação, a fim de evitar que interrupções no atendimento possam ocorrer e ainda que os pacientes tenham que conviver com as manifestações patológicas que possam prejudicar suas condições de saúde.

Face ao exposto, acredita-se que o objetivo deste trabalho tenha sido alcançado, e que ele poderá contribuir para a melhoria das condições da edificação estudada, tendo em vista que possibilitou a identificação das principais manifestações patológicas e seus respectivos graus de risco bem como propôs medidas de reparo. Sendo assim um importante instrumento para auxiliar os gestores do hospital no processo de contratação dos serviços de reparo elencados nesta pesquisa.

\section{Referências}

[1] CUNHA, B. F.; ZIMMERMANN, C. C.; SILVA, J. P. B.; ROMAN, R. R.; OSTROWSKI, R. A. P. Investigação de manifestações patológicas em patrimônio histórico: Estudo de caso do Hospital e Maternidade Carlos Corrêa. In: IX CONGRESO INTERNACIONAL SOBRE PATOLOGÍA Y RECUPERACIÓN DE ESTRUCTURAS, 9., 2013, João Pessoa. Anais... João Pessoa, 2013.

[2] LUDUVICO, T. S. Desempenho a estanqueidade à água: interface janela e parede. 2016. 176p. Dissertação (Mestrado) Universidade Federal de Santa Maria, Santa Maria, 2016.

[3] JARDIM, M. T. M.; ASSIS, L. M. A.; FERNANDES, R. P. S.; FERREIRA, R.P.S.; FERREIRA, J. P.; OLIVEIRA, S. L. Manifestações patológicas na construção civil e recuperação de empreendimento de alvenaria pré-moldada: um estudo de caso de um empreendimento localizado no município de esmeraldas, Minas Gerais. Revista Paramétrica •Vol 11, No 12, Ano 2019•

[4] CAIXETA, M. C. B. F.; FIGUEIREDO, A.; FABRÍCIO, M. M. Desenvolvimento integrado de projeto, gerenciamento de obra e manutenção de edifícios hospitalares. Ambiente Construído, Porto Alegre, v. 9, n. 2, p. 57-72, abr./jun. 2009.

[5] DIETRICH, Y. P.; SATO, V. Y.; VIEIRA, G. L. Manifestações patológicas em hospital de Vitória ES. In: $55^{\circ}$ CONGRESSO BRASILEIRO DO CONCRETO, 55., 2013, Gramado. Anais... São Paulo, 2013.

[6] ARAÚJO, A. P. B. Avaliação dos materiais de revestimentos internos utilizados nas áreas críticas e semicríticas em cinco hospitais de Florianópolis/SC.Trabalho de Conclusão de Curso - Engenharia. Universidade Federal de Santa Catarina, Florianópolis, 2018.

DOI: $10.25286 /$ repa.v6i1.1388 
[7] SAHADE, R. F. Avaliação de sistemas de recuperação de fissuras em alvenaria de vedação. 2005. 169p. Dissertação (Mestrado) - Instituto de Pesquisas Tecnológicas do Estado de São Paulo, São Paulo, 2005.

[8] DUARTE, K. C. D. D. Manifestações patológicas em equipamentos públicos de saúde: estudo de caso. 2018. Trabalho De Conclusão de Curso - Universidade Federal Rural do Semi-Árido, Rio Grande do Norte, 2018.

[9] PEREIRA, S. P.; HIPPERT, M. A. S. ; ABDALLA, J. G. F. Manutenção Corretiva em unidades de atenção primária à saúde na cidade de Juiz de Fora. In: ENCONTRO NACIONAL DE TECNOLOGIA DO AMBIENTE CONSTRUÍDO, 14., 2012, Juiz de Fora. Anais... Porto Alegre: ANTAC, 2012.

[10] PEREIRA, M. F. P. Anomalias em paredes de alvenaria sem função estrutural. 2005. 489p. Dissertação (Mestrado) - Universidade do Minho, Guimarães, 2005.

[11] GONÇALVES; A. BRITO, J.; AMARO, B. Systematic Approach to Inspect, Diagnose, and Repair Masonry Walls. Journal of Performance of Constructed Facilities, Virgínia, v. 29, n. 6. 2015.

[12] SILVA, J. M. Alvenarias não estruturais: patologias e estratégias de reabilitação. In: SEMINÁRIO SOBRE PAREDES DE ALVENARIA, 2002, Porto. Anais... Porto, 2002.

[13] SHIRAKAWA, M. A.; MONTEIRO, M. B.; SELMO, S. M. S.; CINCOTTO, M. A. Identificação de fungos em revestimentos de argamassa com bolor evidente. In: I SIMPÓSIO BRASILEIRO DE TECNOLOGIA DAS ARGAMASSAS, 1., 1995, Goiânia. Anais... Goiás, 1995.

[14] GUERRA, F. L.; CUNHA, E. G.; SILVA, A. C. S. B; KNOP, S. Análise das condições favoráveis à formação de bolor em edificação histórica de Pelotas, RS, Brasil. Ambiente Construído, Porto Alegre, v. 12, n. 4, p. 7-23. 2012.

[15] CORREIA, A. F. G. Análise de risco com recurso à FMEA: Propostas para a graduação da severidade e ocorrência. 2016. Dissertação (Mestrado em Engenharia Civil) - Faculdade de Engenharia, Universidade do Porto, Porto, 2016.

[16] MARTINS, N. P.; PESSOA, R.; NASCIMENTO, R. Priorização na resolução de manifestações patológicas em estruturas de concreto armado.
Revista de Engenharia e Pesquisa Aplicada. Recife, v. 2, n. 3, p. 138 - 148, 2017.

[17] PRUDENTE, R. R. Análise e classificação de solicitações de assistência técnica em empreendimentos residenciais verticais pelo método FMEA (Failure Mode and Effect Analysis). Revista Especialize On-line IPOG - Goiânia - Ano 10, Edição no 17 Vol. 01 Julho/2019

[18] SILVA, S. R. C.; FONSECA, M.; BRITO, ]. Metodologia FMEA e suas aplicações à construção de edifícios. In: ENCONTRO NACIONAL SOBRE QUALIDADE E INOVAÇÃO NA CONSTRUÇÃO, 1, 2006, Lisboa. Anais... Lisboa, 2006.

[19] YIN, R. K. Estudo de Caso - Planejamento e Métodos. 2 ed. São Paulo: Bookman, 2001.

[20] INSTITUTO BRASILEIRO DE AVALIAÇÕES E PERÍCIAS DE ENGENHARIA DE SÃO PAULO IBAPE/SP. Inspeção Predial: a Saúde dos Edifícios. São Paulo: IBAPE/SP, 2012.

[21] CUPERTINO, D.; BRANDSTETTER, M. C. G. de $O$. Proposição de ferramenta de gestão pósobra a partir dos registros de solicitação de assistência técnica. Ambiente Construído, Porto Alegre, v. 15, n. 4, p. 243-265, out./dez. 2015.

[22] LORDSLEEM JR., A. C. Sistemas de recuperação de fissuras da alvenaria de vedação: avaliação da capacidade de deformação. 1997. 174p. Dissertação (Mestrado) - Escola Politécnica da Universidade de São Paulo, São Paulo, 1997.

[23] MAGALHÃES, E. F. Fissuras em alvenarias: configurações típicas e levantamento de incidências no estado do Rio Grande do Sul. 2004. 180p. Dissertação (Mestrado) - Universidade Federal do Rio Grande do Sul, Porto Alegre, 2004.

[24] PAZ, L. A. F.; COSTA, C. A.; PAULA, M. O.; ALMEIDA, W. J. D., FERNANDES, F. A. S. Levantamento de patologias causadas por umidade em uma edificação na cidade de Palmas - TO. Revista Eletrônica em Gestão, Educação e Tecnologia Ambiental, Santa Maria, v. 20, n. 1, p. 174 - 180, jan./abr. 2016.

[25] POSSER, N. D. Proporcionamento de argamassas para reboco de recuperação. 2004. 180p. Dissertação (Mestrado) - Universidade Federal do Rio Grande do Sul, Porto Alegre, 2004. 